\title{
Microbial communities in the estuarine water areas of the rivers in the southeastern part of Lake Baikal
}

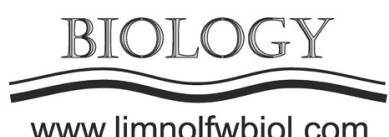

www.limnolfwbiol.com

\author{
Zemskaya T.I., Bukin S.V.*, Zakharenko A.S., Chernitsyna C.M., Shubenkova O.V.
}

Limnological Institute of the Siberian Branch of the Russian Academy of Sciences, Ulan-Batorskaya 3, 664033 Irkutsk, Russia.

\begin{abstract}
Using the Illumina MiSeq platform, we have studied the diversity of bacteria and archaea in three rivers of the southeastern end of Lake Baikal in the under-ice period of 2018. In analysed 16S rRNA gene libraries of all rivers, we have identified sequences of 12 bacterial phyla: Actinobacteria, Bacteroidetes, Cyanobacteria, Elusimicrobia, Epsilonbacteraeota, Fibrobacteres, Firmicutes, Omnitrophicaeota, Patescibacteria, Planctomycetes, Proteobacteria, and Verrucomicrobia. The contribution of minor taxa to the microbiomes from the estuaries of the rivers Solzan and Bolshaya Osinovka is more significant. Three phyla (Thaumarchaeota, Euryarchaeota and Crenarchaeota) and one superphylum (DPANN) represent archaea. The diversity of bacteria and archaea in the investigated ecotopes has its specifics and is different to that found in the pelagic zone of Southern Baikal. Bacteria show phylogenetic diversity at the level of families and genera, whereas archaea - at the level of phyla. In the microbiomes, we have identified microorganisms involved in various stages of transformation of organic and inorganic substances.
\end{abstract}

Keywords: small tributaries of Lake Baikal, microbial communities, diversity and structure, 16S rRNA gene, Illumina MiSeq

\section{Introduction}

Rivers and their estuarine water areas are zones, where transformation and accumulation of various substances from shores and river waters take place (Newton et al., 2013; 2015; Cloutier et al., 2015). The depth of information acquired by using advanced molecular genetic approaches provides a means to characterize the microbial composition, distribution, and transportation pathways in the environment and to relate them to understand pollution mechanisms (Newton et al., 2013; Halliday et al., 2014). There was the active destruction of various substances in the estuarine water areas of large tributaries of Lake Baikal: the rivers Selenga and Upper Angara (Maksimenko et al., 2008; 2012; Sorokovikova et al., 2012), and to a lesser extent - in water areas small inflowing tributaries (Maksimov, 1995). There were practically no studies concerning the diversity of microbial communities in these areas; only the taxa ratio at the phylum level were investigated in rivers and estuarine water areas of the rivers Selenga and Upper Angara. At the same time, some works state that precipitation (Khodzher et al., 2002; Sorokovikova et al., 2002; Tomberg et al., 2016) as well as domestic sewage (Drucker et al., 1993; Shtykova et al., 2016) and groundwater runoff from sludge and lignin storage pits of the closed Baikalsk Pulp and Paper Mill (State Report..., 2017) influence the chemical composition in the rivers of Southern Baikal.

In the under-ice period of 2018, we conducted comprehensive studies at estuaries and estuarine water areas of small rivers in the southeastern part of Lake Baikal (Zemskaya et al., 2019). We found that acidity of snow cover and waters of the Pereyomnaya River did not adversely affect the abundance of microorganisms and their productiveness. The high values of dark carbon dioxide fixation in the water of the estuaries of the rivers in comparison with the estuarine zone were a distinctive feature of these water areas, and the high $\mathrm{P} / \mathrm{B}$ coefficients (specific bacterioplankton production) with a significantly lower total microbial count indicated a high percentage of metabolically active cells that ensure the inclusion of carbon not only in the bacterioplankton biomass but also other organic compounds. Therefore, we were interested in the study of the diversity and structure of microbial communities at the estuary and an estuarine water area of the Pereyomnaya River as well as estuaries of the rivers Solzan and Bolshaya Osinovka having the acidity of snow cover and inflow of wastewater from sludge and lignin storage pits, using the Illumina MiSeq platform. 


\section{Material and methods 2.1. Study areas and sampling}

The water studies were carried out in March 2018 at estuaries and an estuarine water area of the Pereyomnaya River as well as the estuaries of the rivers Solzan and Bolshaya Osinovka (Southern Baikal). Water was sampled using a Niskin bottle at the estuaries of the rivers and a distance of 100 and $200 \mathrm{~m}$ from the estuaries. A description of the stations, methods for studying chemical parameters and $\mathrm{pH}$ are shown in (Zemskaya et al., 2019).

\subsection{DNA extraction}

We obtained five DNA samples from the surface water. Water samples $(5 \mathrm{~L})$ were filtered on nitrocellulose filters ( $25 \mathrm{~mm}$ diameter, 0.2 micron pore size; "Millipore", Germany) using a diaphragm pump. The filter was then placed in a TE buffer ( $10 \mathrm{mM}$ Tris-HCl, $\mathrm{pH} 7.4 ; 1 \mathrm{mM}$ EDTA, $\mathrm{pH}$ 8.0) and frozen at $-20^{\circ} \mathrm{C}$. Then, it was transported to the laboratory. DNA was extracted according to the modified method of phenol-chloroform extraction (Sambrook et al., 1989). The extracted DNA was kept at $-70^{\circ} \mathrm{C}$ for further use. The universal primers U341F (5'-CCTACGGGRSGCAGCAG-3') and U785R (5'- GACTACHVGGGTATCTAATCC -3') as well as a program: $96^{\circ} \mathrm{C}$ for $3 \mathrm{~min} ; 96^{\circ} \mathrm{C}$ for $30 \mathrm{~s} ; 55^{\circ} \mathrm{C}$ for $30 \mathrm{~s}$; $72^{\circ} \mathrm{C}$ for $40 \mathrm{~s}$ (25 cycles); and $72^{\circ} \mathrm{C}$ for $10 \mathrm{~min}$, were used for PCR amplification of 16S rRNA gene fragments of bacteria, including the variable region V3-V4. The primers that included the variable region V2-V3: A113F (5'-ACKGCTSAGTAACACGTGG-3') and A520R (5'-TACGGCGGCKGCTGGCA-3') (Whitehead and Cotta, 1999; Kim et al., 2011), as well as a program: $96^{\circ} \mathrm{C}$ for 2 $\min ; 96^{\circ} \mathrm{C}$ for $30 \mathrm{~s}, 58^{\circ} \mathrm{C}$ for $45 \mathrm{~s}, 72^{\circ} \mathrm{C}$ for $40 \mathrm{~s}$ ( 25 cycles); and $72^{\circ} \mathrm{C}$ for $10 \mathrm{~min}$, were used for PCR amplification of $16 \mathrm{~S}$ rRNA gene fragments of archaea. The libraries were analysed using Illumina MiSeq Standard Kit v.3 (Illumina) at the Genomics Core Facility of the Evrogen Join Stock company (Moscow).

\subsection{Data preparation and filtering: Bioinfor- matics analysis}

Paired-end sequencing reads were trimmed and filtered by quality using leading and sliding window trimming with the average Phred-value $=25$ and window size $=13-15$ bases in Trimmomatic version 0.39 (Bolger et al., 2014). The R1 and R2 sequences corresponding to ribosomal RNA amplicons were merged into contigs with the mothur merge.contigs command. The fragments obtained were filtered by size and tested on the contents of respective forward/ reverse primers with allowing two mismatch between forward and reverse primer and sequence. Further rRNA sequence processing was performed using mothur v.1.34.4 software (Schloss et al., 2009) according to MiSeq SOP recommendations (Kozich et al., 2013). To compare the microbial diversity among the samples, the bacterial read numbers of each sample were subsampled to those of the sample with the smallest number of reads by random removal of sequencing reads using the sub. sample command of the mothur program. The filtered sequences were aligned, clustered, and identified taxonomically using the SILVA 132 databases (http:// www.arb-silva.de). To estimate similarity among bacterial communities, the samples were analysed using non-metric multidimensional scaling and clustered on the basis of the Euclidean distance matrix by the Vegan and Cluster packages in R. For statistical analysis and assessment of the association of individual OTUs with chemical parameters, the concentrations of $\mathrm{O}_{2}, \mathrm{POB}$, $\mathrm{SO}_{4}{ }^{2-}$, and $\mathrm{CH}_{4}$ shown in (Zemskaya et al., 2019) were used. The closest homologues of each gene fragment sequence were found with a BLAST search against the NR database (http://blast.ncbi.nlm.nih.gov). The 16S rRNA sequences were deposited in the NCBI's Sequence Read Archive (Accession number: Bioproject PRJNA556789).

\section{Results and discussion}

The obtained rarefaction curves (data not shown) indicate that the sequencing volume reached in the analysis of the samples is satisfactory for the complete characterisation of diversity of bacterial communities from river samples but insufficient for the reference station. In the latter sample, we obtained the sequences of almost one taxon, cyanobacteria, which differed significantly from the data simultaneously obtained in the pelagic zone of Southern Baikal (Cabello-Yeves et al., 2018). In river microbiomes, the Chao1 and Shannon indices were maximum for $16 \mathrm{~S}$ rRNA gene libraries of bacteria from the Solzan River (4471.3 and 6.8, respectively) as well as for archaea from the estuarine water area of the Pereyomnaya River (138 and 4.2, respectively, Table 1 ). The number of archaeal species varied less significantly; the highest values of the Shannon index (4.2) were in the estuarine water area of the Pereyomnaya River, and the lowest ones (3.3) - at the estuary of the Solzan River. Notably, the lower number of the obtained archaeal sequences in comparison with bacterial ones may be due to their low abundance and an insufficient amount of investigated DNA.

Analysis of the 16S rRNA gene libraries of bacteria and archaea in the rivers and estuarine water areas indicated a different taxonomic composition of the communities. OTUs of bacteria and archaea formed two clusters each on dendrograms. The first one included sequences from the estuary and estuarine water area of the Pereyomnaya River, and the second - from the estuaries of the rivers Solzan and Bolshaya Osinovka (Fig. 1A, 1B). Based on the intracluster distances, the diversity of bacterial communities was more similar in the microbiomes from the estuarine water area of the Pereyomnaya River than between microbiomes from the estuary and estuarine water area. According to intercluster distances, the differences in the composition of archaeal communities were more obvious in comparison with bacterial communities.

In the analysed 16S rRNA gene libraries of all rivers, there were sequences of 12 bacterial 
phyla: Actinobacteria, Bacteroidetes, Cyanobacteria, Elusimicrobia, Epsilonbacteraeota, Fibrobacteres, Firmicutes, Omnitrophicaeota, Patescibacteria, Planctomycetes, Proteobacteria, and Verrucomicrobia (Fig. 2A). The contribution of minor taxa varied: their diversity and percentage of sequences were lower in the microbiome from the water area of the Pereyomnaya River and higher at the estuaries of the rivers Solzan and Bolshaya Osinovka (4.7 and 2.1\%) (Fig. 2B). In the microbiome from the estuary of the Pereyomnaya River, the sequences of Proteobacteria (46\%), Epsilonbacteraeota (21\%) and Bacteroidetes (11.2\%) as well as Cyanobacteria (7.8\%) and Patescibacteria (4.1\%) had the highest percentage. At a distance of $100 \mathrm{~m}$ from the river estuary, the ratio of the dominant taxa in the microbiomes changed, with an increase in the contribution of the members of the phyla Firmicutes (8.5\%), Bacteroidetes (18.2\%) and Cyanobacteria (18.3\%) and decrease in Proteobacteria (25.1\%). At a distance of $200 \mathrm{~m}$ from the river estuary, the ratio of taxa in the microbiomes again changed; the members of Bacteroidetes (26.3\%), Cyanobacteria (25.5\%) and Gammaproteobacteria (25.3\%) had the highest percentage, and the sequences of Firmicutes $(0.2 \%)$ and Epsilonbacteraeota (4.1\%) were minor. Microorganisms of the Gammaproteobacteria (20.0-32.4\%) mainly represented Proteobacteria with a large contribution of the sequences of the order Betaproteobacteriales. Among them, we identified the sequences of methano- and methylotropic bacteria, in particular, the members of the families Methylophilaceae (genus Methylotenera) and Methylomonaceae (genus Methylobacter). The presence of a great number of sequences of these taxa at the estuary of the Pereyomnaya River is likely due to their inflow with the runoff of the river, which flows
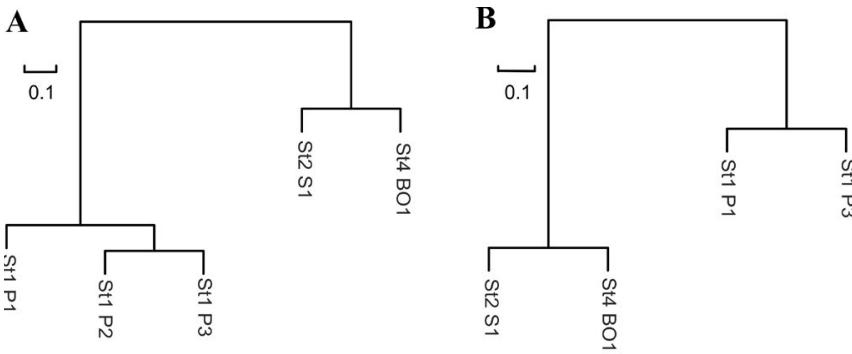

Fig.1. Dendrogram of similarity and difference of bacterial (A) and archaeal (B) communities based on Euclidean distance matrix

through wetlands. Moreover, the microbiome of this river $(11.7 \%)$ had a high percentage of the sequences of the genus Methylobacterium (Alphaproteobacteria), which also participate in the methane cycle, ensuring the methanol oxidation. In the communities of the estuarine water area of the Pereyomnaya River (2.8 and $4.8 \%$, respectively), the members of this genus were a minor component. The bacterial sequences of the genus Sphingomonas (Alphaproteobacteria), which closest homologues have proteo- and lipolytic activity and are capable of surviving under low concentrations of nutrients (Yoon et al., 2008), had a large contribution in the microbiomes of all investigated samples.

Members of the Deltaproteobacteria class in the Pereyomnaya River and its water area were not numerous $(1.9 \%$ or less) and included both aerobic predatory bacteria of the genus Bdellovibrio and anaerobic sulphate- (genus Desulfobulbus) and metalreducing microorganisms (genus Geobacter). The sequences of the phylum Bacteroidetes (11.2-22.5\%), which belong to both planktonic (Flavobacterium, Fluviicola, Arcicella, and Parasediminibacterium) and

Table 1. Indices of species richness and diversity (at a cluster distance of 0.03 ) of bacteria and archaea in the 16 rRNA gene libraries of microbial communities from the rivers Pereyomnaya, Solzan and Bolshaya Osinovka.

\begin{tabular}{|c|c|c|c|c|c|c|c|c|}
\hline \multicolumn{2}{|c|}{ Sampling area, sample } & $\begin{array}{l}\text { Number } \\
\text { of reads }\end{array}$ & $\begin{array}{c}\text { Coverage, } \\
\%\end{array}$ & $\begin{array}{c}\text { Number of } \\
\text { OTU }_{0.03}\end{array}$ & ACE & Chao1 & $\begin{array}{l}\text { Simpson's } \\
\text { Inverse } \\
\text { Index }\end{array}$ & Shannon \\
\hline \multicolumn{9}{|c|}{ Bacteria } \\
\hline $\begin{array}{l}\text { estuary of the Pereyomnaya } \\
\text { River }\end{array}$ & St1 P1 & 148453 & 99.6 & 3821 & 4110.4 & 4171.2 & 15.0 & 4.67 \\
\hline $100 \mathrm{~m}$ from the estuary & St1 P2 & 106195 & 99.1 & 3086 & 3781.9 & 3701.2 & 12.4 & 4.24 \\
\hline $200 \mathrm{~m}$ from the estuary & St1 P3 & 100175 & 99.1 & 3301 & 3986.3 & 3987.0 & 14.4 & 4.66 \\
\hline estuary of the Solzan River & St2 S1 & 162003 & 99.9 & 4432 & 4471.3 & 4509.7 & 218.1 & 6.79 \\
\hline $\begin{array}{l}\text { estuary of the Bolshaya } \\
\text { Osinovka River }\end{array}$ & St4 BO1 & 104767 & 99.4 & 4110 & 4375.9 & 4442.7 & 97.6 & 6.40 \\
\hline reference station & St5 Fon & 2941 & 99.9 & 8 & 11.8 & 9.0 & 1.0 & 0.05 \\
\hline \multicolumn{9}{|c|}{ Archaea } \\
\hline $\begin{array}{l}\text { estuary of the Pereyomnaya } \\
\text { River }\end{array}$ & St1 P1 & 1117 & 99.2 & 80 & 83.9 & 86.0 & 15.0 & 3.6 \\
\hline $200 \mathrm{~m}$ from the estuary & St1 P3 & 1670 & 99.4 & 123 & 125.6 & 138.0 & 37.4 & 4.2 \\
\hline $200 \mathrm{~m}$ from the estuary & St2 S1 & 1278 & 99.4 & 66 & 69.1 & 70.6 & 15.2 & 3.3 \\
\hline $\begin{array}{l}\text { estuary of the Bolshaya } \\
\text { Osinovka River }\end{array}$ & St4 BO1 & 637 & 98.9 & 80 & 81.9 & 82.3 & 27.7 & 3.9 \\
\hline
\end{tabular}


A

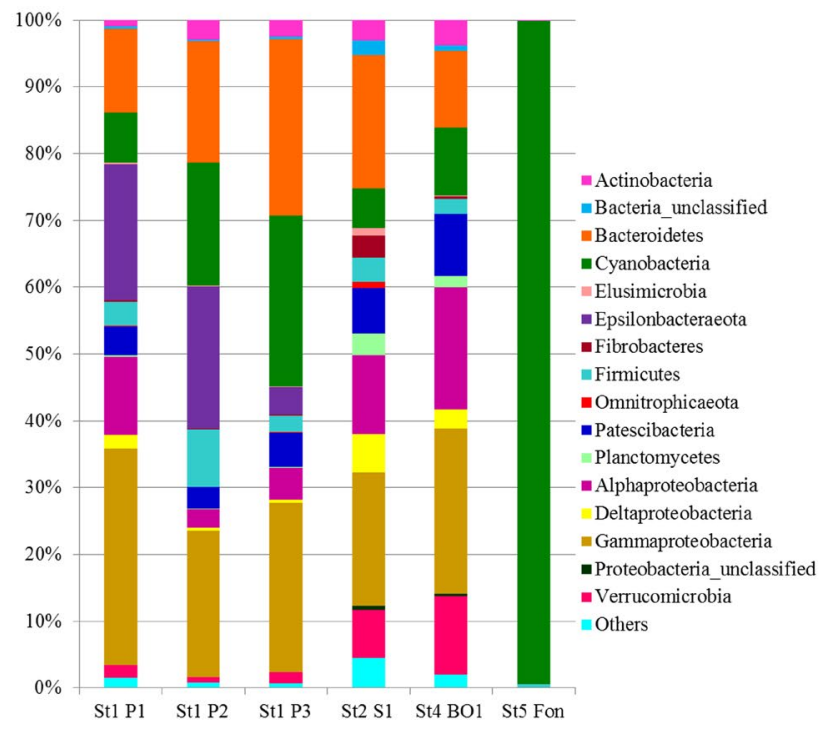

B

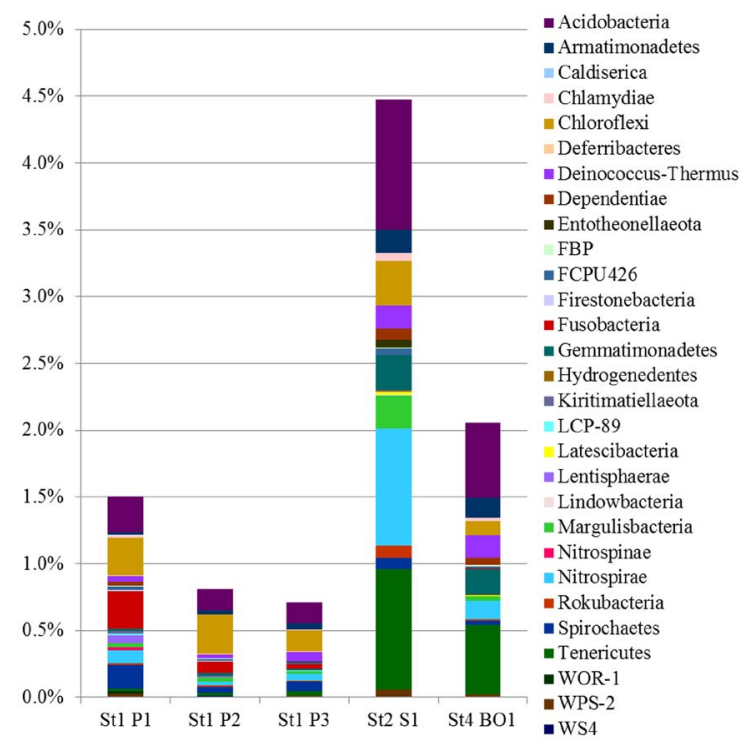

Fig.2. The composition of the bacterial community in the water of the rivers Pereyomnaya, Solzan and Bolshaya Osinovka according to the analysis of sequences of $16 \mathrm{~S}$ rRNA gene fragments: A - dominant phyla (share of sequences $>95.0 \%$ ); B - minor taxa (share of sequences $<5.0 \%$ ) The composition of the bacterial community in the water of the rivers Pereyomnaya, Solzan and Bolshaya Osinovka according to the analysis of sequences of 16S rRNA gene fragments: A - dominant phyla (share of sequences $>95.0 \%$ ); B - minor taxa (share of sequences $<5.0 \%$ )

benthic microorganisms (Paludibacter), were more diverse and numerous in the microbiomes of this area. The identified bacteria of the genera Flavobacterium and Fluviicola are capable of decomposing plant polysaccharides, such as starch, cellulose, xylans and pectins, as well as photosynthesizing due to the presence of rhodopsins in the cells (Humphry et al., 2001; Martinez-Garcia et al., 2011; Feng et al., 2015; Park et al., 2017). Additionally, bacteria of the genera Arcicella and Parasediminibacterium play an important role in protein metabolism (Sheu et al., 2010; Kang et al., 2016), whereas the Paludibacter members ferment sugars (Ueki, 2006).

Microbiome in the Solzan River had a wider range of bacterial taxa (Fig. 2A), including dominant Gammaproteobacteria (20\%), Alphaproteobacteria (11.8\%) and Bacteroidetes (20.1\%). In the microbiome of this river, the contribution of Patescibacteria $(6.8 \%)$ and Verrucomicrobia (Opitutaceae family, 7.2\%) increased, and that of Cyanobacteria (5.9\%) decreased. Like in the microbiomes of the Pereyomnaya River, members of the order Betaproteobacteriales, in particular, the sequences of the genera Paucibacter and Rhodoferax, were numerous among Gammaproteobacteria. The strains of the genus Paucibacter from lake sediments can cleave cyanobacterial hepatotoxins, microcystins and nodularin (Rapala et al., 2005). In the microbiome of the Solzam River, the share of minor taxa increased (4.5\%), among which the intracellular parasites of arthropod from the phylum Tenerecutes (Mycoplasmataceae family, 0.9\%) (Kostanjsek et al., 2007) as well as ammonia- and nitrite-oxidizing bacteria of the phylum Nitrospirae (genus Nitrospira, 0.9\%) (Koch et al., 2015) and Acidobacteria (approximately 1\%) were the most representative. Furthermore, in the minor component of the microbiome, there were members of the phyla Planctomycetes, Omnitrophicaeota, Fibrobacteres, and
Firmicutes. A wider range of taxa in the microbiome of this river may be due to the influx of water and microorganisms from sludge and lignin storage pits remaining after the closure of Baikalsk Pulp and Paper Mill.

The structure and diversity of the microbiome from the Bolshaya Osinovka River were similar to those from the Solzan River. Gammaproteobacteria (24.7\%), Alphaproteobacteria (18.3\%), Bacteroidetes (11.6\%), Verrucomicrobia (11.6\%), and Patescibacteria (9.3\%) were among the dominant phyla. The contribution of minor taxa did not exceed $2 \%$. Notably, in the microbiomes of the Solzan and Bolshaya Osinovka Rivers, there was a decrease in the contribution of the sequences of sulphur-oxidizing bacteria (genus Sulfurospirillum) from the phylum Epsilonbacteraeota $(0.01 \%)$, which had a high percentage in the microbiomes from the Pereyomnaya River (up to $21 \%$ ).

The taxonomic composition of archaea was less diverse (Fig. 3) in the investigated areas. We identified members of three phyla (Thaumarchaeota, Euryarchaeota

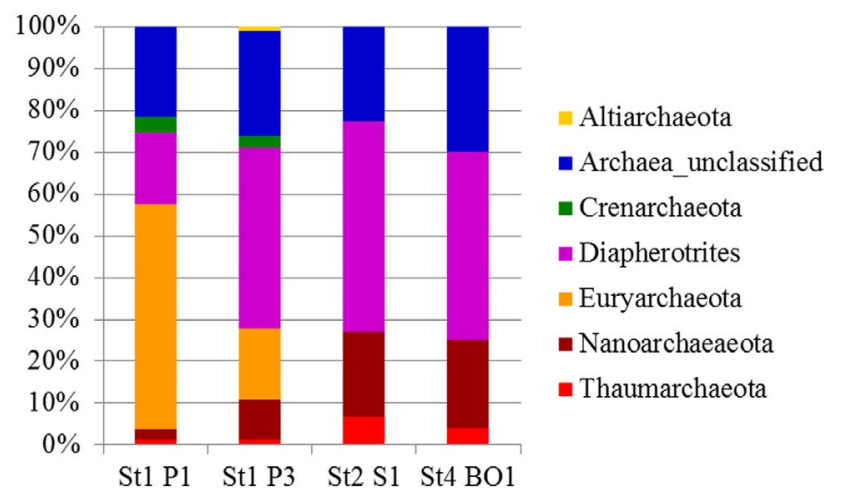

Fig.3. The composition of archaeal community in the water of the rivers Pereyomnaya, Solzan and Bolshaya Osinovka according to the analysis of the sequences of $16 \mathrm{~S}$ rRNA gene fragments 

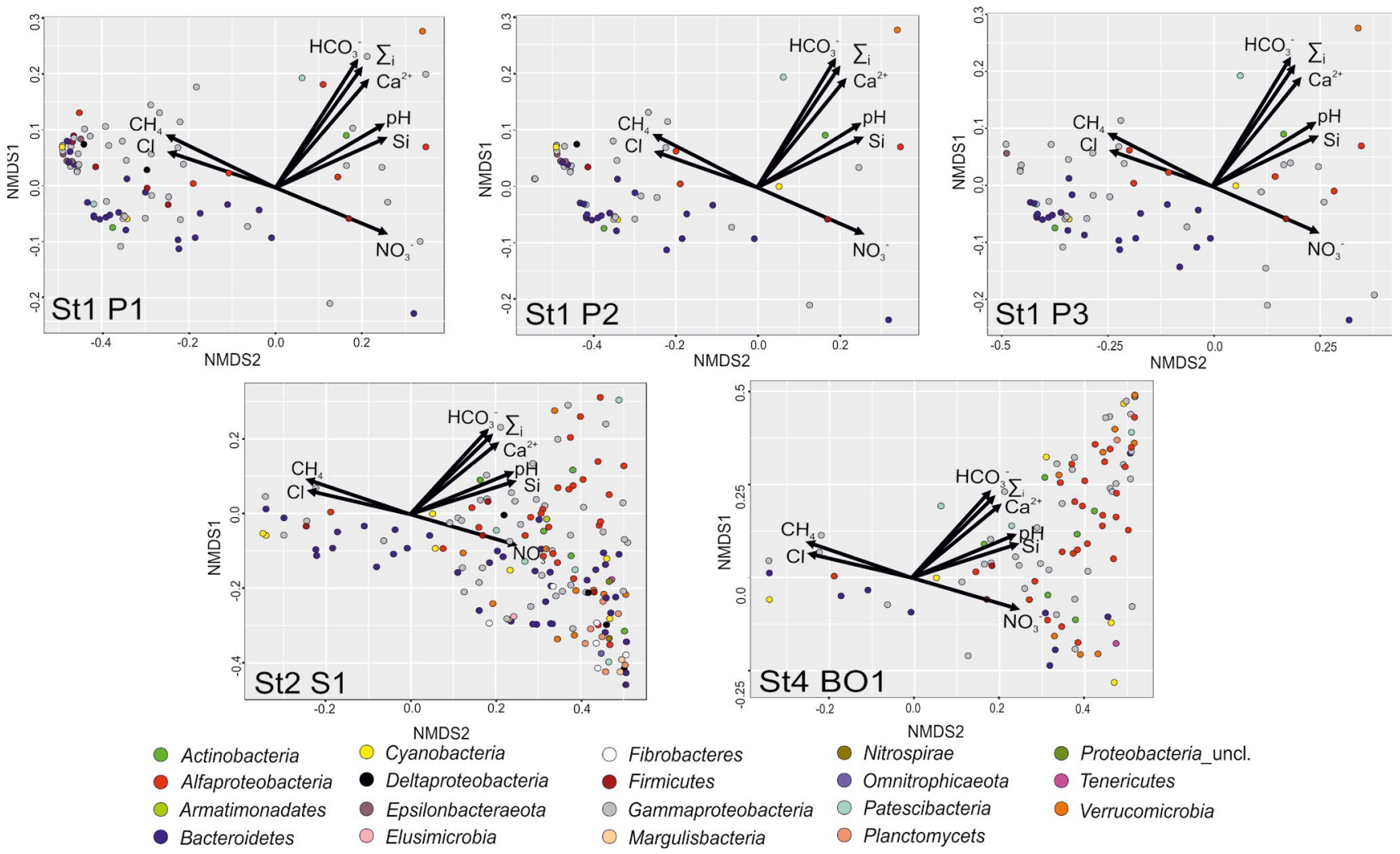

Fig.4. Non-metric multidimensional scaling (NMDS) ordination of bacterial community composition in each sample based on Euclidean distances calculated for abundant OTUs with more than 150 sequences (stress $=1.37$ ). Vectors show correlations of environmental variables $(\mathrm{p}<0.05)$

and Crenarchaeota) and one superphylum (DPANN) of archaea. Unlike the archaeal community from the photic layer of the pelagic zone in Southern Baikal, where there were only members of the phylum Thaumarchaeota (Cabello-Yeves et al., 2018), microbiomes of the studied rivers had a more diverse taxonomic composition. The contribution of the Thaumarchaeota members is insignificant (1.1-6.7\%), and the revealed sequences belong to ammonium-oxidizing microorganisms of the families Nitrosopumilaceae and Nitrosotaleaceae (Park et al., 2012). The microbiome from the water area of the Pereyomnaya River had the greatest number of archaeal taxa, and at the estuary, the bulk of sequences belonged to the methanogenic archaea of the phylum Euryarchaeota (53.9\%); in the estuarine water area, their contribution was much smaller (16.9\%), and they were not detected in the communities from other rivers. The members of Crenarchaeota were also found in minor quantities only in the microbiomes from the Pereyomnaya River (3.8-2.6\%), and the Diapherotrites and Nanoarchaeota members of the DPANN superphylum dominated the microbiomes of the rivers Solzan and Bolshaya Osinovka (from 20.3 to $50.4 \%$ ). Notably, the sequences of the DPANN superphylum were observed only in the near-bottom area of the pelagic zone in Southern Baikal (Cabello-Yeves, personal communication).

The nonmetric multidimensional scaling technic evaluated the association of the individual taxonomic units and chemical indicators in the studied biotopes (Fig. 4, Fig. 5). The analysis included OTUs having more than 150 sequences. To construct dendrograms for data array on bacteria, we used such parameters as decomposable organic matter (DOM), a total number of ions, the concentration of major ions as well as $\mathrm{pH}$. The dendrograms show the data on the association of chemical parameters with the individual OTUs of bacteria (Fig. 4) and archaea (Fig. 5). It is obvious that three clusters of bacterial OTUs form in each water area. In the microbiomes of the Pereyomnaya River and its water area, the OTU group associated with the concentration of $\mathrm{Cl}^{-}$and $\mathrm{CH}_{4}$ ions is the most evident. This cluster includes members of such taxa as Bacteroidetes, Alpha- and Gammaproteobacteria, among which the most representative are the sequences of the families Methylophilaceae (genus Methylotenera) and Methylomonaceae (genus Methylobacter) involved

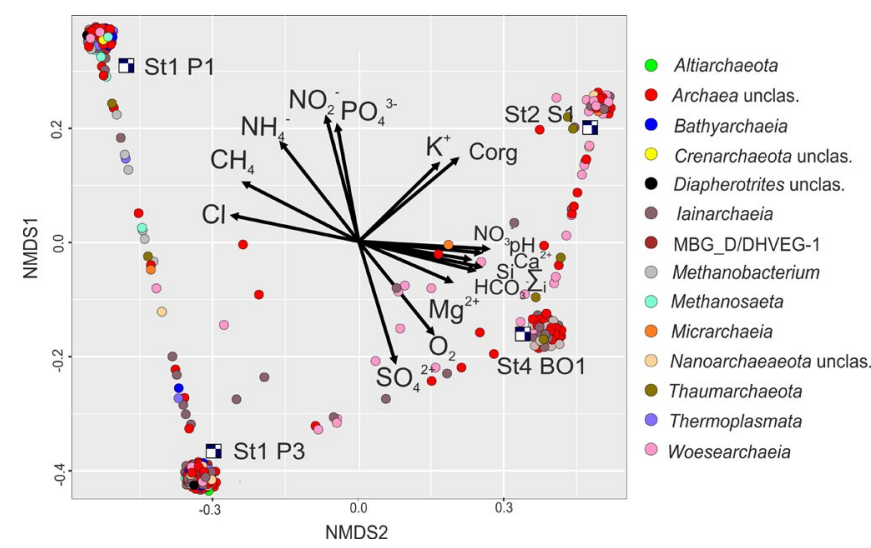

Fig.5. Non-metric multidimensional scaling (NMDS) ordination of archaeal community composition in each sample based on Euclidean distances calculated for abundant OTUs with more than 50 sequences (stress $=1.74$ ). Vectors show correlations of environmental variables 
in various stages of methane oxidation. Among Bacteroidetes, the members of the genera Paludibacter, Arcicella and Flavobacterium are numerous. In the microbiomes of the rivers Solzan and Bolshaya Osinovka, a large number of OTUs is associated with the total number of ions, the concentration of $\mathrm{Ca}^{2+}$, $\mathrm{Si}$ and $\mathrm{HCO}_{3}^{-}$ions as well as the $\mathrm{pH}$ of the water. In this cluster, the most representative sequences are Alpha- (families Caulobacteraceae, Hyphomonadaceae, Paracaedibacteraceae, Rhodobacteraceae, and Rickettsiaceae), Gammaproteobacteria (Burkholderiaceae, Chitinibacteraceae, Rhodocyclaceae, Cellvibrionaceae, and Pseudomonadaceae) and Actinobacteria (Microbacteriaceae and Solirubrobacteraceae). The third OTU cluster is the most numerous in the microbiomes of the rivers Solzan and Bolshaya Osinovka, and it correlates with the concentration of nitrate ion. This cluster has OTUs of Gammaproteobacteria (Burkholderiaceae; Alphaproteobacteria Xanthomonadaceae), (Hyphomonadaceae; Rhodobacteraceae; Sphingomonadaceae), Tenerecutes, Verrucomicrobia (Rubritaleaceae), Planctomycetes (Pirellulaceae), and Nitrospiraceae (Nitrospira).

The analysis of data array of the archaeal OTUs indicates their different contribution to the composition of the communities in the studied water areas (Fig. 5) and the lack of reliable associations with most on the analysed parameters. This is most evident for the archaeal community from the water area of the Pereyomnaya River, where we have determined no reliable correlation between dominant OTUs with any of the parameters. The individual OTUs of archaea from the Bolshaya Osinovka River are associated with nitrates, the total number of the $\mathrm{Si}$ and $\mathrm{HCO}_{3}^{-}$ions as well as the $\mathrm{pH}$ of the water (Fig. 5), whereas in the Solzan River - with the concentration of DOM and potassium ions.

\section{Conclusions}

The studied rivers have different salinity, the $\mathrm{pH}$ of the water, the concentration of DOM and individual ions, which affected the diversity of microbial communities. The phylogenetic analysis has shown that their diversity and structure in the rivers are not the same and differ from those simultaneously observed in the pelagic zone (Cabello-Yeves et al., 2018). The level of families and genera mostly shows the taxonomic difference in bacteria, and the level of phyla - in archaea. In the communities of the Pereyomnaya River and its water area, where the waters have the lowest salinity and mildly acidic $\mathrm{pH}$ of the environment, the sequences of bacteria involved in various stages of methane oxidation predominated in the microbiomes. This is consistent with higher methane concentrations at the estuary and estuarine water of this river in comparison with other rivers. The taxonomic composition of the communities in the estuarine water area is similar to riverine and pelagic communities. At a distance from the river estuaries, the contribution of the members of Patescibacteria and Epsilonbacteraeota, as well as minor taxa, decreases. Despite the smaller watershed basin and runoff in comparison with the Pereyomnaya River, the microbiomes of the rivers Solzan and Bolshaya Osinovka have a more diverse phylogenetic composition. This is most likely due to the inflow of wastewater from the sludge and lignin storage pits of Baikalsk Pulp and Paper Mill, which ensure the activity of a wide range of microorganisms. Moreover, the structure of bacterial communities in the rivers differs from the structure of the communities from the photic layer of the pelagic zone in Southern Baikal (5 and $20 \mathrm{~m}$ ) (Cabello-Yeves et al., 2018). In all microbiomes, the contributions of Gammaproteobacteria, Alphaproteobacteria and Bacteroidetes are comparable, whereas in the microbiomes of rivers, the phyla Patescibacteria and Epsilonbacteraeota are more representative, and Actinobacteria are less representative. Probably, the small representation of the latter ones in the river biotopes during the under-ice period is due to a dense snow cover that does not let in sunlight and, hence, limits the development of photoheterotrophic bacteria. In the pelagic zone of Southern Baikal, where the ice was less covered with snow, actinobacteria with a photoheterotrophic type of metabolism prevailed, whereas, in the river microbiomes, chemoorganotrophic microorganisms capable of using various substrates as well as methane were the most representative. High metabolic activity in the river samples compared to those from the estuarine water area of the Pereyomnaya River implies the lack of a mixing zone typical of large tributaries, which serves as a kind of biofilter that impedes the influx of various compounds in the lake waters.

\section{Acknowledgements}

The study was supported by the grant OFI-M No. 17-29-05040 and the LIN SB RAS State Task 03452019-0007 (No. AAAA-A16-116122110064-7).

\section{References}

Bolger A.M., Lohse M., Usadel B. 2014. Trimmomatic: a flexible trimmer for Illumina sequence data. Bioinformatics 30: 2114-2120. DOI:10.1093/bioinformatics/btu170

Cabello-Yeves P.J., Zemskaya T.I., Rosselli R. et al. 2018. Genomes of Novel Microbial Lineages Assembled from the Sub-Ice Waters of Lake Baikal. Applied and Environmental Microbiology 84: 1-21. DOI: 10.1128/AEM.02132-17

Cloutier D.D., Alm E.W., Mclellan S.L. 2015. Influence of land use, nutrients, and geography on microbial communities and fecal indicator abundance at Lake Michigan beaches. Applied and Environmental Microbiology 81: 4904-4913. DOI: 10.1128/AEM.00233-15

Drucker V.V., Kostornova T.Ya., Molozhavaya O.A. et al. 1993. Water quality assessment of Lake Baikal by sanitary and bacteriological indicators. Geography and natural resources 1: 60-64.

Feng X.-M., Tan X., Jia L. etal. 2015. Flavobacteriumbuctense sp. nov., isolated from freshwater. Archives of Microbiology 197: 1109-1115. DOI:10.1007/s00203-015-1149-5

Halliday E., Mclellan S.L., Amaral-Zettler L.A. et al. 2014. Comparison of bacterial communities in sands and water at beaches with bacterial water quality violations. PLoS One 9. DOI: $10.1371 /$ journal. pone.0090815 
Humphry D.R., George, A., Cummings, S.P. et al. 2001. Flavobacterium frigidarium sp. nov., an aerobic, psychrophilic, xylanolytic and laminarinolytic bacterium from Antarctica. International Journal of Systematic and Evolutionary Microbiology 51: 1235-1243. DOI:10.1099/00207713-51-4-1235

Kang H., Joung Y., Kim H. et al. 2016. Parasedimini bacterium paludis gen. nov., sp. nov., isolated from wetland. International Journal of Systematic and Evolutionary Microbiology 66: 326-331. DOI:10.1099/ijsem.0.000719

Khodzher T.V., Semenov M.Yu., Obolkin V.A. et al. 2002. Monitoring of acid deposition in the Baikal region. Chemistry for Sustainable Development 10: 569-575. (in Russian)

Kim M., Morrison M., Yu Z. 2011. Evaluation of different partial 16S rRNA gene sequence regions for phylogenetic analysis of microbiomes. Journal of Microbiological Methods 84: 81-87. DOI:10.1016/j.mimet.2010.10.020

Koch H., Lücker S., Albertsen M. et al. 2015. Expanded metabolic versatility of ubiquitous nitrite-oxidizing bacteria from the genus Nitrospira. Proceedings of the National Academy of Sciences 112: 11371-11376. DOI:10.1073/ pnas. 1506533112

Kostanjsek R., Strus J., Avgustin G. 2007. "Candidatus Bacilloplasma," a Novel Lineage of Mollicutes Associated with the Hindgut Wall of the Terrestrial Isopod Porcellio scaber (Crustacea: Isopoda). Applied and Environmental Microbiology 73: 5566-5573. DOI:10.1128/aem.02468-06

Kozich J.J., Westcott S.L., Baxter N.T. et al. 2013. Development of a dual-index sequencing strategy and curation pipeline for analyzing amplicon sequence data on the MiSeq Illumina sequencing platform. Applied and Environmental Microbiology 79: 5112-5120. DOI: 10.1128/AEM.01043-13

Maksimenko S.Y., Zemskaya T.I., Pavlova O.N. et al. 2008. Microbial community of the water column of the Selenga River-Lake Baikal biogeochemical barrier. Microbiology 77: 587-594. DOI: 10.1134/S0026261708050123

Maksimenko S.Yu., Ivanov V.G., Buryukhaev S.P. et al. 2012. The structure of microbial communities in the confluence zone of the Upper Angara River in Lake Baikal. Gidrobilogichesky zhurnal [Hydrobioogical journal] 48: 55-68. (in Russian)

Maksimov V.V. 1995. Microbiology of large Baikal rivers and their estuarine water areas. Cand. Sc. Dissertation, Irkutsk State University, Irkutsk, Russia. (in Russian)

Martinez-Garcia M., Swan B.K., Poulton N.J. et al. 2011. High-throughput single-cell sequencing identifies photoheterotrophs and chemoautotrophs in freshwater bacterioplankton. The ISME Journal 6: 113-123. DOI:10.1038/ismej.2011.8

Newton R.J., Bootsma M.J., Morrison H.G. et al. 2013. A microbial signature approach to identify fecal pollution in the waters off an urbanized coast of Lake Michigan. Microbial Ecology 65: 1011-1023. DOI: 10.1007/s00248-013-0200-9

Newton R.J., Mclellan S.L., Dila D.K. et al. 2015. Sewage reflects the microbiomes of human populations. mBio 6. DOI: 10.1128/mBio.02574-14

Park S.J., Kim J.G., Jung M.Y. et al. 2012. Draft Genome Sequence of an Ammonia-Oxidizing Archaeon, "Candidatus Nitrosopumilus koreensis" AR1, from Marine Sediment. Journal of Bacteriology 194: 6940-6941. DOI:10.1128/jb.01857-12

Park M., Nam G.G., Kim S. et al. 2017. Flavobacterium chuncheonense sp. nov. and Flavobacterium luteum sp. nov., isolated from a freshwater lake. International Journal of
Systematic and Evolutionary Microbiology 67: 4409-4415. DOI:10.1099/ijsem.0.002304

Rapala J., Berg K.A., Lyra C. et al. 2005. Paucibacter toxinivorans gen. nov., sp. nov., a bacterium that degrades cyclic cyanobacterial hepatotoxins microcystins and nodularin. International Journal of Systematic and Evolutionary Microbiology 55: 1563-1568. DOI: 10.1099/ ijs.0.63599-0

Sambrook J., Fritsch E.F., Maniatis T. 1989. Molecular Cloning: A Laboratory Manual. N.Y.: Cold Spring Harbor Laboratory Press.

Schloss P.D., Westcott S.L., Ryabin T. et al. 2009. Introducing mothur: Open-Source, Platform-Independent, Community-Supported Software for Describing and Comparing Microbial Communities. Applied and Environmental Microbiology 75: 7537-7541. DOI:10.1128/aem.01541-09

Sheu S.Y., Yang C.S., Chen M.H. et al. 2010. Arcicella aurantiaca sp. nov., isolated from stream water. International Journal of Systematic and Evolutionary Microbiology 60: 2979-2983. DOI:10.1099/ijs.0.021527-0

Shtykova Yu.R., Suslova M.Yu., Kostornova T.Ya. et al. 2016. Sanitary and microbiological monitoring of the Lake Baikal pelagical zone and Baikal's major triburaries from 2010 to 2015. Izvestiya Irkutskogo Gosudarstvennogo Universiteta. Seriya «Biologiya. Ekologiya» [The bulletin of Irkutsk State University. Series «Biology. Ecology»] 17: 50-61. (in Russian)

Sorokovikova L.M., Sinyukovich V.N., Korovyakova I.V. et al. 2002. The formation of the chemical composition of the water in the tributaries of Southern Baikal under modern conditions. Geografiya i Prirodnye Resursy [Geography and Natural Resources] 4: 52-57. (in Russian)

Sorokovikova L.M., Popovskaya G.I., Belykh O.I. et al. 2012. Plankton composition and water chemistry in the mixing zone of the Selenga River with Lake Baikal. Hydrobiologia 695: 329-341. DOI 10.1007/s10750-012-1200-3

State report on the state and environmental protection of the Irkutsk Region in 2016 / Ministry of Natural Resources and Ecology of Irkutsk Region. 2017. Irkutsk: Megaprint LLC (in Russian)

Tomberg I.V., Sorokovikova L.M., Netsvetaeva O.G. et al. 2016. Chemical composition and trends of oxidation of snow waters and waters of South Baikal tributaries. Optika Atmosfery i Okeana [Atmospheric and Oceanic Optics] 29: 516-520. DOI: 10.15372/AOO20160612 (in Russian)

Ueki A. 2006. Paludibacter propionicigenes gen. nov., sp. nov., a novel strictly anaerobic, Gram-negative, propionateproducing bacterium isolated from plant residue in irrigated rice-field soil in Japan. International Journal of Systematic and Evolutionary Microbiology 56: 39-44. DOI:10.1099/ ijs.0.63896-0

Whitehead T., Cotta M. 1999. Phylogenetic diversity of methanogenic archaea in swine waste storage pits. FEMS Microbiology Letters 179: 223-226. DOI:10.1111/j.1574-6968.1999.tb08731

Yoon J.H., Kang S.J., Lee S.Y. et al. 2008. Sphingomonas insulae sp. nov., isolated from soil. International Journal of Systematic and Evolutionary Microbiology 58: 231-236. DOI:10.1099/ijs.0.65075-0

Zemskaya T.I., Zakharenko A.S., Rusanov I.I. et al. 2019. Ecology of estuarine basins of southern Baikal small rivers according to springtime chemical and microbiological investigation. Microbiology 88: 1-13. DOI: 10.1134/ S002636561906020X 